\title{
Rhizosphere 5 - shining light on the world beneath our feet
}

\author{
Andrea Schnepf $\mathbb{D}$ - Xinhua He
}

Received: 30 March 2021 / Accepted: 31 March 2021 / Published online: 8 April 2021

(C) The Author(s) 2021

\section{Soil-Plant interactions are important for climate change mitigation}

The Marschner Review of Silva and Lambers (2021) proposes a quantitative framework for the integrated analysis of plant functional groups under climate change that includes scaling rules by which local soil-plantatmosphere interactions can be spatially and temporally aggregated to infer emergent ecosystem properties. This model is analysed in the commentary of Penuelas and Sardans (2021), who concluded that it would help to apply soil-plant-atmosphere interaction research in climate-change mitigation and adaptation actions. In

Responsible Editor: Hans Lambers.

This special issue of Plant and Soil contains selected papers from the Rhizosphere 5 conference "Shining light on the world beneath our feet" that was held in Saskatoon, Canada, from 7 to 11 July 2019. In addition to regular research articles, this special issue includes two Marschner Reviews as well as two commentaries.

\footnotetext{
A. Schnepf $(\bowtie)$

IBG-3 (Agrosphere), Forschungszentrum Jülich GmbH, Wilhelm Johnen Str., 52428 Jülich, Germany

e-mail: a.schnepf@fz-juelich.de

X. He

Centre of Excellence for Soil Biology, College of Resources and Environment, and Key Laboratory of Eco-environments of Three Gorges Reservoir Region, Ministry of Education, School of Life Sciences, Southwest University, Chongqing 400716, China e-mail: xinhua.he@uwa.edu.au

X. He

School of Biological Sciences, University of Western Australia, Perth, WA 6009, Australia
}

other words, this approach can shed light on the feedback between small-scale rhizosphere processes and large-scale climate processes. Although vital for plants, belowground functional traits are studied less because they are hard to measure. One approach to circumvent this problem is to find aboveground proxies that allow conclusions on belowground processes.

\section{Assessing below-ground traits from above-ground observations}

Lambers et al. (2021) established that leaf manganese $(\mathrm{Mn})$ concentrations are a signature of phosphorus $(\mathrm{P})$ mobilising carboxylates in the rhizosphere in low-P soils across 727 species in Australia and New Zealand. In their commentary on this paper, White and Neugebauer (2021) conclude that, although some orders containing species accumulating $\mathrm{Mn}$ in their shoots are typically non-mycorrhizal and release carboxylates into the rhizosphere, such as the Proteales, many orders containing species with this trait are characterised by conventional mycorrhizal associations. It remains to be further investigated if mycorrhizas really play a role in $\mathrm{P}$ acquisition in these Mn-accumulating mycorrhizal species, or whether carboxylates are more important.

Francioli et al. (2021) investigated the saprophytic fungi associated with roots of eight plant species - either a grass or a forb - along a biodiversity gradient in a grassland experiment. Plant functional group was the main factor driving fungal saprophytic community 
structure of species when growing in monoculture, likely driven by inherent differences in root lignin concentration and $\mathrm{C}: \mathrm{N}$ ratio between grasses and forbs. This clear differentiation at the level of plant functional groups also worked out when analysing saprotrophic communities in mixed root samples. The saprophytic fungal communities in plant species mixtures represented to a large extent the differences observed in monocultures, suggesting that the root-associated saprophytic community can be predicted using information on plant functional groups in grasslands.

\section{Special root-rhizosphere traits for plant nutrient acquisition can be found around the world}

Nutrient-poor soils occur in western Japan, where a native Cyperaceae species is shown to form specialised "dauciform" roots. Masuda et al. (2021) confirmed P mobilization in the rhizosheath soil of the dauciform roots of Carex lenta which significantly contributed to $\mathrm{P}$ acquisition in its nutrient-poor habitat. Rhizosheath formation can also be important in agricultural crops. In a pot experiment using calcareous soil at three levels of soil $\mathrm{Zn}$ and P, He et al. (2021) investigated zinc (Zn) and $\mathrm{P}$ interactions of alfalfa, a deep-rooted leguminous perennial plant (Medicago sativa) that is widely cultivated for forage and hay. Rhizosheath properties of alfalfa showed strong P-Zn interactions in the calcareous soilplant system that significantly affect $\mathrm{Zn}$ bioavailability, plant growth, accumulation of $\mathrm{Zn}$ and $\mathrm{P}$, and partitioning of $\mathrm{Zn}$. Therefore, rational $\mathrm{P}$ fertilisation should be considered for efficient $\mathrm{Zn}$ biofortification on $\mathrm{Zn}$-deficient soils and phytoremediation of $\mathrm{Zn}$ contaminated soils. Honvault et al. (2021) found that plant $\mathrm{P}$-acquisition strategies are driven by multiple belowground morphological and physiological traits as well as interactions among these traits. Interactions and trade-offs among belowground functional traits, however, remain underexplored, especially for fast-growing crops such as cover crops, limiting our understanding of $\mathrm{P}$ cycling in agroecosystems. Examining 13 cover crop species highlighted trade-offs between thicker and thinner roots with thicker roots exhibiting greater carboxylate-release or phosphatase activity in the rhizosheath. Multivariate analysis underlined four main P-acquisition strategies relying primarily on morphological traits, physiological traits, or a combination thereof, and mediated by soil type. The diverse strategies underpin functionally-complementary multispecies crop designs via preferential access to different soil P pools, enhancing $\mathrm{P}$ availability and cycling efficiency.

\section{Below-ground traits that explain:}

Geographic distribution of plants

Phosphorus availability can partly explain the distribution of two native Australian plant species. Albornoz et al. (2021) established that this can be explained by the plant specie's ability to down-regulate their P-uptake capacity. In their study, they demonstrated that Anigozanthos flavidus, a species with a wider geographic distribution, is much more effective a down-regulating its P-uptake capacity at high $\mathrm{P}$ availability than Macropidia fuliginosa, a species with a narrower distribution.

Success of re-vegetation of mining land

Restoration of mined land in semi-arid Western Australia was the focus of Cross et al. (2021a). They found that the growth of six keystone native plant species was compromised at different life cycle stages in restoration substrates compared with natural topsoil. In particular, root development was constrained, primarily because of a lack of available nitrogen $(\mathrm{N})$ and high alkalinity. Their results suggest that the edaphic properties of restoration substrates must be considered early in restoration planning, allowing practitioners to select the most appropriate pioneers and ensure favourable revegetation outcomes. In a further study, Cross et al. (2021b) confirmed this result for most of 40 native plant species and eight crops. Their results suggest that up to $75 \%$ of native floristic biodiversity might be selected against in the ecological restoration of magnetite tailings landforms. The best-performing species were those with calcicole plant strategies and $\mathrm{N}_{2}$-fixing or cluster-rootproducing species, indicating that consideration of plant functional traits such as nutrient-acquisition strategy may be important when selecting species as potential pioneers in ecological restoration and rehabilitation.

Plant nutrient $(\mathrm{P}, \mathrm{Fe})$ acquisition

Cawthray et al. (2021) undertook solution culture experiments to measure root-mediated iron $(\mathrm{Fe})$ reduction $(\mathrm{FeR})$ in cluster roots at four stages of cluster-root 
development, in non-cluster roots and whole root systems for two species of Banksia (B. attenuata and B. laricina) grown at 2 to $300 \mu \mathrm{M} \mathrm{Fe}$ (as Fe-EDTA). Unlike typical Strategy I species, both Banksia species showed no significant variation in FeR, for either cluster or non-cluster roots over this wide range of Fe supply. They also observed only minor differences for wholeroot system FeR, and even though B. attenuata showed signs of leaf Fe deficiency in the $2 \mu \mathrm{M}$ Fe treatment, its FeR was the lowest of both species across all treatments. Additionally, taking plants through a pulse from low to high Fe supply, then back to low Fe supply, did not elucidate any significant response in FeR. They concluded that although Fe acquisition is tightly controlled in the investigated Banksia species, such control is not based on regulation of FeR, which challenges the model that is commonly accepted for Strategy I species.

Mechanisms of endophytic fungi to facilitate salt tolerance in host crops

Gupta et al. (2021) reviewed the functioning of salt-tolerant microorganisms, i.e. endophytic, symbiotic fungi, to plant genetics or soil management to alleviate salt stress in crops. Such functions are attained through the induction of systemic resistance, increase of beneficial metabolites, and activation of antioxidant systems to scavenge reactive oxygen species, as well as modulation of plant phytohormones. Colonisation by the endophytic fungus improves nutrient uptake and maintains ionic homeostasis by modulating ion accumulation, thus restricting sodium $(\mathrm{Na}+)$ transport to leaves and ensuring a high cytosolic potassium $(\mathrm{K}+): \mathrm{Na}+$ ratio. Participating endophytic fungi enhance transcripts of genes encoding the High-Affinity Potassium Transporter 1 (HKT1) and inward rectifying $\mathrm{K}+$ channels KAT1 and KAT2, which regulate $\mathrm{K}+$ and $\mathrm{Na}+$ homeostasis. In addition, endophyte-induced strigolactones play regulatory roles in salt tolerance by interacting with phytohormones. This progress on endophytic symbioses under salinity sheds light on our understanding of the mechanisms of endophytic fungi to enhance salt tolerance in host crops.

\section{Modelling combined with experiments can be used to quantify specific $P$ acquisition processes}

McKay Fletcher et al. (2021) present a new approach that combines microdialysis and modelling to quantify citrate-enhanced P uptake by roots. Microdialysis probes with citrate in the perfusate absorb similar quantities of $\mathrm{P}$ to an exuding root. The combination with the model allows to decouple microdialysis and rhizosphere mechanisms. Knowing the microdialysis setup, the model thus allows to determine rhizosphere mechanisms from the measurements. Using their model setup, they found that a plant needs to exude citrate at a rate of $0.73 \mu \mathrm{mol} \mathrm{cm}-1$ of root $\mathrm{h}-1$ for a significant increase in $\mathrm{P}$ uptake; a rate much higher than is commonly produced by a single root. Such quantifications can help to understand the effects of root exudation for different types of roots and root systems including cluster roots and dauciform roots.

\section{Root microbiome research as a new imperative in the field of plant-microbe interactions}

In their Marschner review, Pieterse et al. (2021) reported that root microbiome research has emerged as a new imperative in the field of plant-microbe interactions. The realisation that thousands of microbial species are an integral part of the biology of plants and expand their genomic potential comes with great new opportunities for microbiome-assisted agriculture. Discoveries that root microbiota support plant growth, nutrition and health fostered bio-based crop system approaches to reduce use of agrochemicals. Since its discovery in 1988, the plant-beneficial rhizobacterium Pseudomonas simiae WCS417 served as a model strain in numerous investigations on how free-living mutualists colonise the rhizosphere, modulate plant immunity, promote plant growth, and influence microbe-microbe interactions in the soil. Pieterse et al. (2021) highlight the key discoveries that have been made with this strain and lay out conceptual frameworks of our current understanding on molecular mechanisms involved in beneficial plantmicrobe interactions, both in binary interactions and in context of the root microbiome.

Author contributions A.S. and X.H. together wrote this editorial. A.S. prepared the submission.

Funding Open Access funding enabled and organized by Projekt DEAL. This work has partially been funded by the German Research Foundation under Germany's Excellence Strategy, EXC-2070-390732324 - PhenoRob. Chongqing Key Laboratory of Plant Resource Conservation and Germplasm Innovation, Biological Science Research Center at Southwest University (100030/ 2120054019), Chongqing, China, and National Natural Science Foundation of China (4111800096). 
Availability of data and material Not applicable.

Code availability Not applicable.

\section{Declarations}

Conflicts of interest/Competing interests Not applicable.

Ethics approval Not applicable.

Consent to participate Not applicable.

Consent for publication Yes.

Open Access This article is licensed under a Creative Commons Attribution 4.0 International License, which permits use, sharing, adaptation, distribution and reproduction in any medium or format, as long as you give appropriate credit to the original author(s) and the source, provide a link to the Creative Commons licence, and indicate if changes were made. The images or other third party material in this article are included in the article's Creative Commons licence, unless indicated otherwise in a credit line to the material. If material is not included in the article's Creative Commons licence and your intended use is not permitted by statutory regulation or exceeds the permitted use, you will need to obtain permission directly from the copyright holder. To view a copy of this licence, visit http://creativecommons.org/licenses/by/4.0/.

\section{References}

Albornoz FE, Shane MW, Lambers H (2021) Contrasting phosphorus sensitivity of two Australian native monocots adapted to different habitats. Plant Soil. https://doi.org/10.1007 /s11104-020-04760-5

Cawthray GR, Denton MD, Grusak MA, Shane MW, Veneklaas EJ, Lambers H (2021) No evidence of regulation in rootmediated iron reduction in two Strategy I cluster-rooted Banksia species (Proteaceae). Plant Soil. https://doi. org/10.1007/s11104-021-04849-5

Cross AT, Ivanov D, Stevens JC, Sadler R, Zhong H, Lambers H, Dixon KW (2021a) Nitrogen limitation and calcifuge plant strategies constrain the establishment of native vegetation on magnetite mine tailings. Plant Soil. https://doi.org/10.1007 /s11104-019-04021-0

Cross AT, Stevens JC, Sadler R, Moreira-Grez B, Ivanov D, Zhong H, Dixon KW, Lambers H (2021b) Compromised root development constrains the establishment potential of native plants in unamended alkaline post-mining substrates. Plant Soil. https://doi.org/10.1007/s11104-018-3876-2

Francioli D, van Rijssel SQ, van Ruijven J, Termorshuizen AJ, Cotton TEA, Dumbrell AJ, Raaijmakers JM, Weigelt A,
Mommer L (2021) Plant functional group drives the community structure of saprophytic fungi in a grassland biodiversity experiment. Plant Soil. https://doi.org/10.1007/s11104-02004454-y

Gupta S, Schillaci M, Walker R, Smith PMC, Watt M, Roessner U (2021) Alleviation of salinity stress in plants by endophytic plant-fungal symbiosis: Current knowledge, perspectives and future directions. Plant Soil. https://doi.org/10.1007/s11104020-04618-w

He H, Wu M, Su R, Zhang Z, Chang C, Peng Q, Dong Z, Pang J, Lambers H (2021) Strong phosphorus (P)-zinc (Zn) interactions in a calcareous soil-alfalfa system suggest that rational $\mathrm{P}$ fertilization should be considered for $\mathrm{Zn}$ biofortification on Zn-deficient soils and phytoremediation of Zn-contaminated soils. Plant Soil. https://doi.org/10.1007/s11104-020-04793W

Honvault N, Houben D, Nobile C, Firmin S, Lambers H, Faucon M-P (2021) Tradeoffs among phosphorus-acquisition root traits of crop species for agroecological intensification. Plant Soil. https://doi.org/10.1007/s11104-020-04584-3

Lambers H, Wright IJ, Guilherme Pereira C, Bellingham PJ, Bentley LP, Boonman A, Cernusak LA, Foulds W, Gleason SM, Gray EF, Hayes PE, Kooyman RM, Malhi Y, Richardson SJ, Shane MW, Staudinger C, Stock WD, Swarts ND, Turner BL, Turner J, Veneklaas EJ, Wasaki J, Westoby $\mathrm{M}, \mathrm{Xu}$ Y (2021) Leaf manganese concentrations as a tool to assess belowground plant functioning in phosphorusimpoverished environments. Plant Soil. https://doi. org/10.1007/s11104-020-04690-2

Masuda G, Maruyama H, Lambers H, Wasaki J (2021) Formation of dauciform roots by Japanese native Cyperaceae and their contribution to phosphorus dynamics in soils. Plant Soil. https://doi.org/10.1007/s11104-020-04565-6

McKay Fletcher DM, Shaw R, Sánchez-Rodríguez AR, Daly KR, van Veelen A, Jones DL, Roose T (2021) Quantifying citrateenhanced phosphate root uptake using microdialysis. Plant Soil. https://doi.org/10.1007/s11104-019-04376-4

Penuelas J, Sardans J (2021) Developing holistic models of the structure and function of the soil/plant/atmosphere continuum. Plant Soil. https://doi.org/10.1007/s11104-020-04641-x

Pieterse CMJ, Berendsen RL, de Jonge R, Stringlis IA, Van Dijken AJH, Van Pelt JA, Van Wees SCM, Yu K, Zamioudis C, Bakker PAHM (2021) Pseudomonas simiae WCS417: star track of a model beneficial rhizobacterium. Plant Soil. https://doi.org/10.1007/s11104-020-04786-9

Silva LCR, Lambers H (2021) Soil-plant-atmosphere interactions: structure, function, and predictive scaling for climate change mitigation. Plant Soil. https://doi.org/10.1007/s11104-02004427-1

White PJ, Neugebauer K (2021) Possible consequences of an inability of plants to control manganese uptake. Plant Soil

Publisher's note Springer Nature remains neutral with regard to jurisdictional claims in published maps and institutional affiliations. 